\title{
Educating designers through Materials Club
}

\section{Zhou, Ziyu $^{\text {a }}$;Rognoli, Valentina ${ }^{a}$ and Ayala-Garcia, Camilo ${ }^{b}$}

${ }^{a}$ Design Department, Politecnico di Milano, Italy, ${ }^{b}$ Design Department, Politecnico di Milano, Italy; Design Department, Universidad de los Andes, Colombia.

\begin{abstract}
Materials education is a crucial element in the field of design. Traditionally, learning about materials is theoretical and book based. However, the appearance of Fab labs in universities add tangible opportunities to enhance materials knowledge. Fab labs combined with classroom didactics create an experimental dimension transforming the original material didactics into participatory activities. This paper aims to analyze how existing Fab lab systems can be reframed to maximize benefits in the material education in the design domain. As a result, we propose the concept of Materials Club. The club is a system made to support design students connecting different resources and facilities to experiment with materials during the development process of their projects. This scenario also promotes methods, which could valorize the existing resources in universities and integrate them into a virtuous system improving current design and material education. We believe that the Materials club can become an essential tool making contribution in materials education.
\end{abstract}

Keywords: Material education; Fab labs; Personal fabrication of materials; Educational community; System design for education. 


\section{Background}

Materials knowledge is considered a fundamental pillar in the field of design (Ashby \& Johnson 2002). It becomes a crucial element of the design education and is catching the attention of scholars' research. Primarily as the traditional ways of educating designers around materials are proven to suffer from a lack of engagement. Secondly, as the learning process around materials should be about handling and interacting with them, rather than learn only through theories and tables. This paper aims to investigate how the materials education changed and evolved in the last ten years, especially in the field of design. By doing so, we formulate the idea of Materials clubs as active and interactive places to learn about materials and do with them.

The didactics of design consists on a series of relationships and mixed theories from a wide range of disciplines. Designers need to have a broader knowledge in different areas and should understand and dialogue in different languages. Materials knowledge have acquired vital importance in the design process, and as a consequence, the way they are taught requires constant improvement. Today materials education in the field of design cannot be only learned from diagrams technical descriptions, but should also include materials experience boards and experimental storytelling. In other words, materials education should shift from a technical and sometimes complex knowledge approach from engineering and materials sciences to experimentation and the involvement of crafts. (Ayala-Garcia, 2014; Nimkulrat, 2012): All this by acknowledging the designer's way of knowing and the different approaches we have to materials.

The phenomenon of digital fabrication laboratories or Fab labs in the last decade has helped enormously in this transition, as students are engaging more with the knowledge of digital crafts and transformation of materials in novel and creative ways. These Fab labs have a high potential to change and switch the original material didactics into participatory activities, also with the help of the internet and the open-sourced communities. Every year thousands of improvements within the labs, the machines and the capabilities for manufacturing different shapes are added by these communities around the globe (Anderson, 2012 p 25). This didactic trend drives our attention as it can enhance materials and design education as well. To help understanding which is the opportunity for material education connecting Fab labs' widespread in universities is essential to highlight the benefit of Fab labs. A Fab lab, which is short for fabrication laboratory, is a small-scale workshop offering personal digital fabrication based on tools and machines for every aspect of the technology development process: design, fabrication, testing and debugging, monitoring and analysis, and documentation (Mikhak et al., 2002). Since 1980's, faculty and employers in universities and research centers started to consider that design graduates have not prepared themselves in doing any real design work. This consideration became important for influencing the design education (Sheppard \& Jenison, 1997) as we give more 
attention to the ability of a designer to do a project with the knowledge he or she acquired. Meanwhile, with a large-range dropping in price of digital fabrication equipment in during the following twenty years, the development of product moved towards the small-scale model type, typical of the design studios (Blikstein, 2013). Both reasons drove the growth of Fab labs in universities. The first Fab lab was born at the Media Lab in Massachusetts Institute of Technology in 2001 (Gershenfeld, 2007), and quickly spread over the world becoming a vibrant global movement. Fab lab shortens the process of turning a students' concept into a real prototype, with its low-cost building. By 2012 many schools and universities announced plans to build digital fabrication and 'making' facilities. The trend became mainstream afterwards (Blikstein, 2013).

This digital manufacturing space, give technical and physical support to design education. Equipped with different small size machines (Namely, CNC, 3D or Laser cutting machines), in Fab labs is possible to produce industrial and electronic projects with raw materials on a small scale (Diez, 2012). Moreover, this democratization of computational media and digital fabrication could drive powerful ideas in design (Astrachan, Hambrusch, Peckham, \& Settle, 2009; Yasar \& Landau, 2003). With high levels of autonomy, students can achieve more knowledge and practice in peer to peer study actions. During the elaboration of prototypes, students are encouraged to brainstorm together and to evaluate each other's work. By doing so, they spark discussions within a co-working atmosphere (Mostert-Van Der Sar, 2013). Also, it gives the possibility of interdisciplinary cooperation, which allows students to acquire different knowledge. In the process of working with the diverse backgrounds, design students can help each other in the process of turning raw materials into an interdisciplinary project (Mostert-Van Der Sar et al., 2013).

As the role of materials is becoming critical in the design process, the ability of the designers to deal with materials is being more emphasized than before. Design students are getting in touch with materials and processes on a different scale. The practical action drives students to think more about the materials and how they can express the features of the design adequately. Also, students get inspired to develop a project through the understanding of specific materials qualities. In the same manner, the material libraries surpass the classical way of teaching materials with engineering manuals and data by inspiring designers with real samples, Fab labs and the DIY approaches transcend the material libraries by encouraging students to tinkering with the materials and learn through experimentation. In this scenario, we believe Materials Club will enhance the design education by adding these labs into a system. This system will connect the students with the different tool which can help in the process of a material transformation. By doing so, Materials education is more likely to become a physical practice than a theoretical acquiring of knowledge. 


\section{From Fab labs to Materials Clubs}

As we mentioned above, Fab Labs are evolving as materials knowledge is becoming a crucial part of the development of a project. We created a concept called Materials Club. We see these Clubs as hybrid systems where physical laboratories and virtual platforms meet to aid designers in the process of materials development. By putting the material at the center of the project, and enabling the different tools of an academic infrastructure, we believe it is possible to engage students to develop meaningful projects, creating materials experiences embedded in their creations. Several scholars have already argued, the importance to create a project starting from the materials (Manzini, 1986); tinkering with the materials as a way to get inspired by their qualities and therefore develop a project enhancing the features of the material (Parisi et al., 2017). Designing using material driven methods (Karana et al., 2015) and dealing with materials in different stages of the process and not only in the selection phase (Rognoli \& Levi, 2011).

For the creation of the Materials Club, we decided to study Politecnico di Milano's school of design laboratory system, which includes Fab Labs such as Polifactory and other labs. One of the primary objectives of this project is to enhance the use of existing resources without the necessity to build specific infrastructure. Sometimes the creation of a new laboratory requires a solid investment and is expected to bring constant research to keep it going. If no projects run on the laboratories, the lack of use the machines and infrastructure could represent a loss of investment and endangerment of the research itself. One of our goals is to connect different laboratories allowing constant use by students and researchers. We started by mapping and understanding the role of the various laboratories that support didactics and how much they contribute to materials education in design. In the current stage of fab labs and laboratories system of the university, we have found some critical points like the lack of connectivity between the labs, the restriction to use a particular machine due to the complexity and how bureaucracy can delay the process during an academic or research project.

\subsection{Turning "passive" material study into the initiative}

The school of Design of Politecnico di Milano, like other design schools, have a straight top-down approach when it comes to laboratories. It contains a considerable amount of laboratories which operating similar to Fab labs with open-source infrastructures for teaching and services. They are spread in different locations around the Lombardy region with various equipment for specific functions and to support particular academic and research activities Within these laboratories students from different levels of education, namely Undergraduate, MSc. and Ph.D. students, create their design projects or handle some interdisciplinary ones. As a politic of the school, students need for security reasons to fulfill different tests for machinery as well as to demonstrate a complete understanding of 
the ways to operate machines and different protocols to deal with the available tools in different labs. This is of particular importance as the university is one of the biggest in Europe and there are too many students accessing the laboratories ${ }^{1}$.

Being so widespread not only in the Milan area but also in Cremona and Lecco regions makes communication through email the more useful way to deal with permission access and related information of operation of laboratories. This system of communication, however, has proven to be less efficient when it comes to the development of a design project, as usually, the time to prototype, construct, test and present a design development during a course, occurs in the last three to four weeks of the course calendar. Another element of great aid and the development of the design project is the material library of Politecnico, the first academic material library (Rognoli, 2005). This material collection has been recently acquired by the library system of the university which has allowed the material samples to be available for online consultancy, but it is now transferred inside one of the libraries of the campus with limited schedule and access.

These resources have significant benefits in design and material didactic. Students are gaining materials knowledge and have well-equipped spaces for developing their prototypes. However, we can strengthen these benefits by enabling students to get achievements more actively. Instead of being managed exclusively by teachers or school managers, students could access and find opportunities independently and proactively to enhance their design study process. In this perspective, we can see that the system of the labs and infrastructures in university could be optimized. By reframing the system, changing students' role inside of it, they can shift from "passively receiving information" to "seek resources and actively share outcomes". It could be a feasible way to maximize the whole process of design, and it will collaborate to fulfill the goal of allowing the materials tinkering, knowledge and development process to be in the early stages of the design process.

\subsection{Broaden the channel for peer learning}

When students work on processing materials in a well-equipped spaces with other peers, they have more willingness to seek resources and share outcomes with each other. Besides, with the interdisciplinary cooperatives occurs more, students demands more on the quantity and quality of communication. Only interactions in labs and other tangible spaces in school cannot satisfy the need for large amount of exchanging knowledge and experience. Therefore, consider the channel of communication is narrow, Materials Club devotes to broaden the way helping students connect with each other. In addition to the

\footnotetext{
1 Politecnico di Milano is the Italian largest university for Engineering, Architecture and Industrial Design and it is ranked as one of the most outstanding European universities in these fields. In QS world university ranking, it ranked fifth in the subject of Art \& Design.
} 
complete offline actions and interactions, the online channel is necessary to enhancing the sense of participation among students and engaging them share their material knowledge. With all the reasons above, we came out the conception of Materials Club.

\section{Conception: the system and organization of Materials Club}

According to the what we could do on the optimization of the lab system in university, there is a scenario to build the network of Materials Club which could connect all the touchpoints and stakeholders. We defined Materials Club as a campus-based system with a combination of tangible spaces and intangible platforms, for enabling design students to understand, get engaged and explore materials more independently.

Systems are complex entities; to understand its behavior is crucial to map and understand the roles of the different stakeholders inside of it. In this stage of the research, the initial mapping provided a more precise picture of integration. Our initial step to understand how the materials club system could work is called LabMap. It can be treated as prima step as well as the foundation for this system because it takes the first step of building connections. It lists the spaces and tools which related to materials all around the campus, with the introduction and highlighting of the benefits students can get from them. We expect to test this LabMap with different students from the BA until the Ph.D. level. This test will allow us to see how by using the various searching functions, students can precisely find what resource could help them to understand the material and its properties, as well as the possible ways to process and experiment with it. (figure 1).
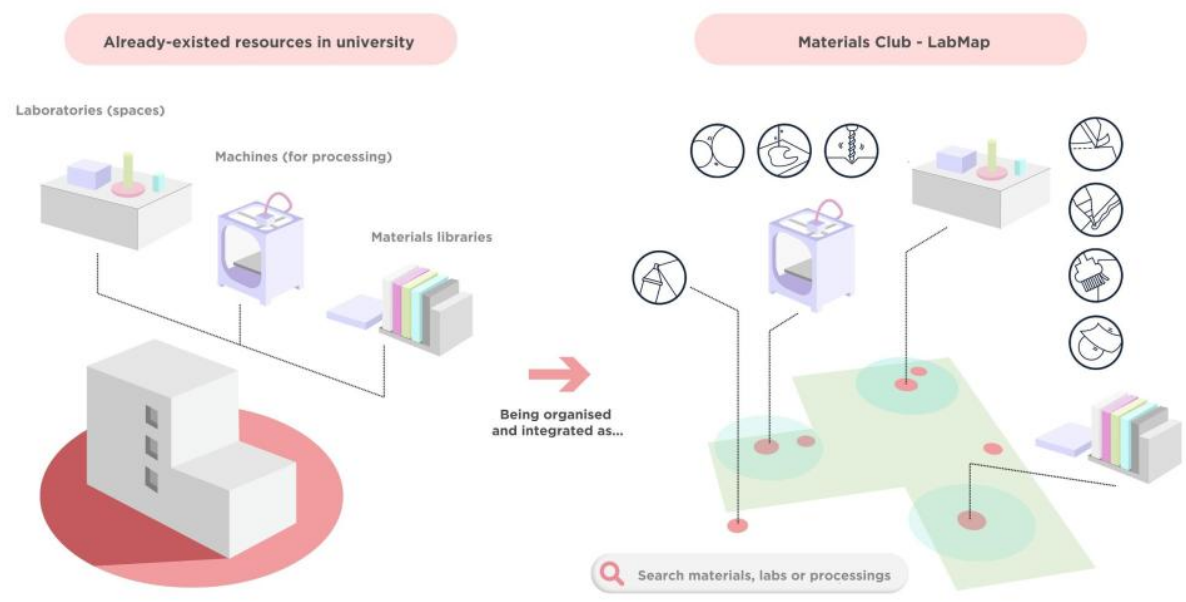

Figure 1. The concept of building the Materials Club-LabMap. 
With the help of LabMap, there is a strong connection between people and infrastructures together, and giving design students more opportunities to interact with materials (select materials tangibly in Materials library; personal fabrication programs in labs). The second step will consist in enriching the system by linking the students into a network: we expect to broaden the channel for engaging peer learning by providing more ways of individual interactions, to reinforce the peer-learning and find material experts. In this case, Materials forum will work as an online community of the Materials Club. A team of professors, researchers, technicians will support students in the different stages of the materials development. Either by providing information about a particular material property or the uses and tricks of a specific machine, It can extend students' learning opportunities outside the physical fab labs.

In this second step, we will test how students interact with the network of the system. Leaving messages to others and get feedback, start a creative discussion, share knowledge or even propose an idea to find cooperative opportunities.

We expect to open the door to design students discovering the world of materials by this enabling system of Materials Club. Although it is in the initial phase of the development, it highlights already the demand for a significant amount of research to carry out. The further studies will suggest possible ways to link every stakeholder and every craft activity related to materials development. At the end of the project, we expect the Materials clubs to become an essential tool in the materials education.

\section{Discussions}

Similarly, how Fab labs brought a revolution in design didactics by shortening the gap between the thinking and the making, we proposed the concept of Materials Clubs as an optimization tool for the materials education. We can say that Materials Club is an entire service system contributing to material education and research by enabling the active interaction theoretical and physical elements of its domain. This open-source community should be flexible, easy-going and co-creative. With it, students get access to information and material knowledge more comfortable and more autonomous.

Because the primary driver of Materials Club is the connection of resources inside the existing lab system of an institution, we believe is a model with high levels of applicability.

Furthermore, Materials Club could enrich the network of Fab labs and Fab cities. As Diez states, with the development of personal fabrication, the open source philosophy both in software and hardware becomes more accessible to the masses and are being shared all over the world (Diez, 2012). The future of production and its relation to the environment will 
rely on the different connection of systems of production, and we believe materials education through Materials Clubs can be one of the various strategies to make it possible.

\section{References}

Anderson, C. (2012) Makers-The New Industrial Revolution. Random House Business Books.

Ayala-Garcia, C. Ayala, C. (2014) Experimenting with Materials - A source for designers to give meaning to new applications, Proceedings of the Design and Emotion Conference 2014 (pp. 408-417). Bogota: Universidad de los Andes.

Astrachan, O., Hambrusch, S., Peckham, J., \& Settle, A. (2009). The present and future of computational thinking. The 40th ACM technical symposium on Computer science education, Chattanooga, TN, USA.

Blikstein, P. (2013). Digital Fabrication and 'Making' in Education: The Democratization of Invention. In J. Walter-Herrmann \& C. Büching (Eds.), FabLabs: Of Machines, Makers and Inventors. Bielefeld: Transcript Publishers.

Diez, T. (2012). Personal Fabrication: Fab Labs as Platforms for Citizen-Based Innovation, Microcontrollers to Cities, Nexus Netw J 14 (2012) 457-468.

Gershenfeld, N. (2007). Fab: the coming revolution on your desktop--from personal computers to personal fabrication. Basic Books (AZ).

Karana E., Barati B., Rognoli V., LaanA.Z.(2015). Material Driven Design (MDD): A Method to Design for Material Experiences. International Journal of Design, Vol. 9 No. 22015

Manzini, E. (1986). La Materia dell'Invenzione [The Material of Invention], Milano, Arcadia.

Mikhak, B., Lyon, C.,\& Gorton, T. (2002). Fab Lab: an alternate model of ICT for development. "Development by design" (dyd02) Bangalore ThinkCycle. Retrieved 6 July 2013, from http://cba.mit.edu/events/03.05.fablab/fablab-dyd02.pdf

Mostert-Van Der Sar, M., Mulder, I., Remijn, L., and Troxler,P., Fablabs in design education. International Conference of Engineering and product design education 5 \& 6 September 2013, Dublin Institute of Technology, Dublin, Ireland.

Nimkulrat, N. (2012). Hands on Intellect: Integrating craft practice into design research. In: International Journal of Design, 6(3). pp.14

Parisi, S., Rognoli, V., Sonneveld, M. (2017) Material Tinkering. An inspirational approach for experiential learning and envisioning in product design education, The Design Journal, 20:sup1, S1167-S1184 
Rognoli, V. Levi, M. (2005). Il senso dei materiali per il design. Milano: Franco Angeli.

Sheppard, S., \& Jenison, R. (1997). Examples of Freshman Design Education. International Journal of Engineering Education, 13(4), 248-261.

Yasar, O., \& Landau, R. H. (2003). Elements of computational science and engineering education. SIAM review, 787-805. 